\title{
Costs of Spinal Cord Injury in Australia
}

\author{
J. Walsh, BSc, AIA, FIAA, ASA
}

1 Rook Street, Hunter's Hill, 2110 NSW, Australia.

\begin{abstract}
Summary
Available data on spinal cord injury in Australia has been synthesised. An investigation and discussion has been made into the major financial costs involved in the acute management and ongoing life support systems required by people who have sustained spinal cord injury. The costs are projected to give an estimate of the potential for dollar savings in Australia in reducing the impact of spinal cord injury, either by lowering its incidence or by reducing the resulting devastation. Allowance has been made in these projections for severity of disability, rates of survival, re-employment, hospitalisation and relative use of various aids and appliances. It is estimated that based on an incidence rate of 25 new cases of spinal cord injury per million of population per annum the annual cost by the year 2006 will exceed $\$ 250 \mathrm{~m}$. As the spinal cord injury population ages the propensity of cost is expected to move from acute and medical care to less acute, community based care. Mention is also made of the noneconomic human costs which cannot be quantified in terms of dollars and cents.
\end{abstract}

Key words: Spinal cord injury; Costs.

Awareness of the value of information systems on spinal cord injury has increased progressively in the past few years in all parts of the world including Australia. Indeed a number of initiatives have been taken to formalise and make compatible the methods and structure of such systems (Burke et al., 1986; DeVivo and Fine, 1980). In Australia, 1987 witnessed a formal exchange of views on this subject and part of this exchange involved an analysis of the costs (both economic and non-economic) caused by spinal cord injury; participants in the debate were representative of Medical opinion, Epidemiology, Government, and actuarial science (Menzies Foundation, 1987).

The process involved first of all a series of papers written by participants at the conference. Each paper was discussed by all participants, and amended appropriately by the editorial committee. The edited chapters were then included in the published manuscript co-authored by all participants. In this way we were able to first of all present a first approximation to the costs involved in 
Table I Initial and ongoing costs of spinal cord injury

\begin{tabular}{lcc}
\hline & Paraplegic & Tetraplegic \\
\hline Initial costs (\$'000 once only) & 50 & 70 \\
Acute care & 46 & 70 \\
Home modifications (including appliances etc.) & 14 & 40 \\
Rehabilitation & & \\
& & \\
Ongoing costs (\$'000 per annum) & $6 \cdot 0$ & $6 \cdot 0$ \\
Income support & no specific additional cost \\
Accommodation & $3 \cdot 0$ & $3 \cdot 0$ \\
Transport & $3 \cdot 0$ & 3.0 \\
Ongoing medical and surgical & - & $5 \cdot 0$ \\
Home nursing care & $1 \cdot 5$ & $6 \cdot 0$ \\
Attendant care & $3 \cdot 0$ & $5 \cdot 0$ \\
Equipment and pharmaceuticals & $1 \cdot 0$ & 1.0 \\
Home maintenance & & \\
\hline
\end{tabular}

spinal cord injury as contained throughout the literature and from personal experience; we were then able to fine tune our figures using the collective experience of Australian experts from both Medicine and from Government. This paper summarises and highlights some features of the analysis.

\section{Methodology}

The financial costs of spinal cord injury were conveniently partitioned into three major headings:

1. Initial hospitalisation.

2. Income support.

3. Ongoing care.

The second and third items were grouped as 'ongoing' costs and the first as 'initial' costs and the major contributing items to each heading are presented below, together with the costs agreed to be consumed by each item by a 'typical' paraplegic and tetraplegic casualty (Table I).

The average amount in dollars consumed by each spinal cord injury on each item was established through a consensus as described above. The figures are the best estimates of a group of experts and are supported by the literature. All figures in this paper are in 1987 Australian dollars (i.e. inflation has been ignored) and they err no doubt on the side of conservatism when viewed beside the heads of claim granted to claimants at common law actions (e.g. Donovan, 1987). Our objective was to estimate the actual costs of what is routinely purchased rather than what may be projected as justifiable in pursuit of an adequate settlement.

In order to establish the total cost of spinal cord injury in the Australian community it was necessary firstly to estimate the numbers and ages of paraplegics and tetraplegics living in Australia (so as to estimate ongoing costs) and secondly to project the likely numbers of new spinal cord injuries each year so as to project initial costs and also to gradually supplement the total picture of ongoing costs as new paraplegics and tetraplegics graduate into community life. These figures could be confidently extrapolated from a number of studies on the prevalence 
Table II Baseline prevalence of spinal cord injury and new injuries in each future year

\begin{tabular}{cccccc}
\hline \multicolumn{3}{c}{ Baseline prevalence } & \multicolumn{3}{c}{ New injuries (\% at each age) } \\
\hline Age & Paraplegics & Tetraplegics & Age & Paraplegics & Tetraplegics \\
22 & 450 & 330 & 20 & 50 & 50 \\
27 & 560 & 400 & 30 & 20 & 20 \\
32 & 450 & 540 & 40 & 15 & 15 \\
37 & 480 & 250 & 50 & 10 & 10 \\
45 & 700 & 480 & 60 & 5 & 5 \\
55 & 480 & 300 & Total & 100 & 100 \\
70 & 360 & 220 & & & \\
Total & 3480 & 2520 & & & \\
\hline
\end{tabular}

and incidence of spinal cord injury in Australia (Burke et al., 1986; Walsh, 1986; Paraplegic \& Quadriplegic Association of NSW, 1985). The model for both baseline prevalence and additions in each future year is shown in Table II.

The projections described in Table II were carried out taking account of the heavier mortality experienced by people who have sustained spinal cord injury both in the acute stages and also in the long term. The algorithm for calculating the population in year ' $n$ ' is as follows: $P(n)=P(n-1)+N(n)-D(n)$, where $\mathrm{P}(\mathrm{n}+1)$ is the starting population in year $(n+1), P(n)$ is the starting population in year $n, N(n)$ is the total number of new injuries in year $n$ and $D(n)$ is the number of deaths in year $n$. Both $N(n)$ and $D(n)$ are composite figures derived from a model of age distribution of paraplegic and tetraplegic casualties to which are applied age specific incidence rates and age and duration specific mortality rates respectively.

The results of the projections are presented in Tables III and IV and graphically in Figure 1. The two projections presented represent:

1. The approximate current situation in Australia (400 new spinal cord injuries per annum).

2. An idea of the potential for cost savings if the incidence was reduced to 200 new cases per year.

Explanations of column headings in Tables III and IV are set out below:

$P(n), D(n)$ and $N(n)$ as explained above

$$
T(n)=P(n)+N(n)
$$

$\mathrm{CP}(\mathrm{n}), \mathrm{CN}(\mathrm{n})$ and $\mathrm{CT}(\mathrm{n})$ represent costs incurred during year $\mathrm{n}$ by (respectively) those people alive at the beginning of year $n$, those new spinal cord injuries during year $n$, and the total of these two.

For each of $P(n), N(n)$ and $T(n)$ an average cost per person is obtained, and finally an investigation is made into the relative importance of initial costs $(\mathrm{CN}(\mathrm{n}))$ and recurrent costs $(\mathrm{CP}(\mathrm{n}))$.

\section{Results}

Spinal cord injury is a significant drain on community resources both through the Social Security system and also through compensation by insurance. 


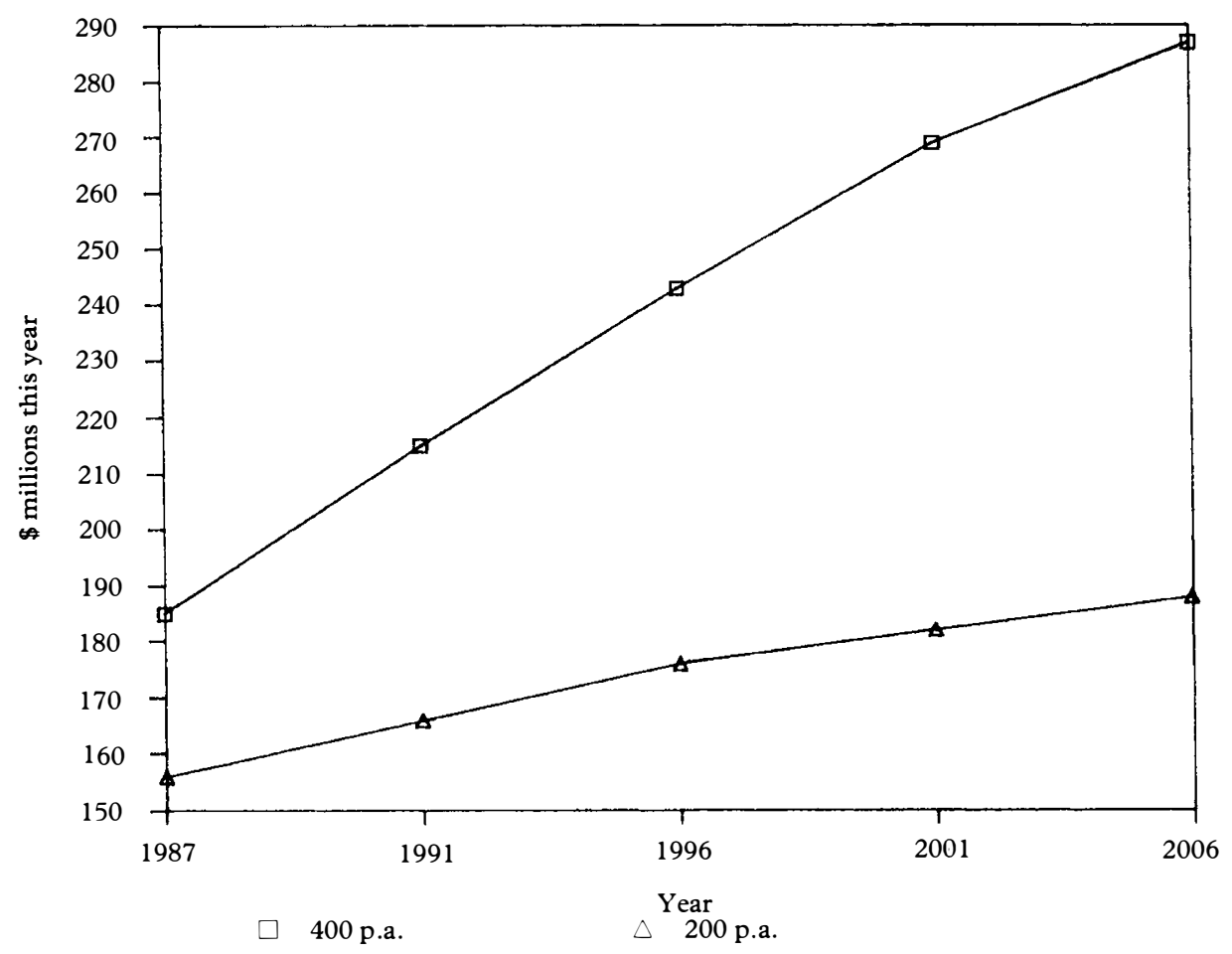

Figure 1 Total future costs of spinal cord injury.

It is estimated that the total cost of spinal cord injury in Australia will rise from $\$ 127 \mathrm{~m}$ per annum in 1987 (excluding new injuries) to $\$ 287 \mathrm{~m}$ or $\$ 188 \mathrm{~m}$ in 2006 based on two projection models (one at 400 new cases of spinal cord injury per year, or 25 per million of population, and alternatively at 200 new cases of spinal cord injury per year or about 12.5 million of population).

It is a valuable planning exercise to further analyse total costs into initial costs and ongoing costs in order to estimate the relative needs in the future. There is no doubt that in Australia we have an expanding spinal cord injury population (that is people are sustaining spinal cord injury at a greater rate than people with spinal cord injury are expiring), and as a result the 'relative needs' pendulum is swinging heavily towards community care. This trend is consistent with experience overseas (Eisenberg and Tierney, 1985; Van Laire and Duyvejonck, 1986) and will continue, particularly as the rate of incidence of spinal cord injury stops rising (Fig. 2, Tables III and IV). There is a suggestion that the rate has already plateaued in Australia but much more information is required before a definitive statement can be made.

Further evidence of the heavy weight contributed by ongoing costs is presented in Figures 3A and 3B. Clearly for both paraplegia and tetraplegia in particular the costs of initial hospitalisation are a minor part in the total cost of spinal cord injury.

The figures on which Figures $3 \mathrm{~A}$ and $3 \mathrm{~B}$ are based are presented in Table V. 
Table III 400 new injuries per annum

\begin{tabular}{|c|c|c|c|c|c|c|c|c|c|c|c|c|}
\hline \multirow{4}{*}{$\begin{array}{c}\text { Year } \\
\text { of } \\
\text { expense } \\
n\end{array}$} & \multicolumn{3}{|c|}{ Projection SCI 1987} & \multicolumn{3}{|c|}{ Projection future SCI } & \multicolumn{3}{|c|}{ Projection total SCI } & \multicolumn{3}{|c|}{ Nature of costs } \\
\hline & No. & $\begin{array}{l}\text { Total } \\
\text { cost }\end{array}$ & Average & $\begin{array}{l}\text { No. } \\
\text { this }\end{array}$ & $\begin{array}{l}\text { Total } \\
\text { cost }\end{array}$ & Average & $\begin{array}{l}\text { Total } \\
\text { no. }\end{array}$ & $\begin{array}{l}\text { Total } \\
\text { cost }\end{array}$ & Average & & & 2 \\
\hline & surviving & $\$ \mathrm{~m}$ & cost & year & $\$ \mathrm{~m}$ & cost & alive & $\$ \mathrm{~m}$ & cost & Initial & Recurrent & - \\
\hline & $\mathrm{P}(\mathrm{n})$ & $\mathrm{CP}(\mathrm{n})$ & $\$ ’ 000$ & $\mathbf{N}(\mathrm{n})$ & $\mathrm{CN}(\mathrm{n})$ & $\$ ’ 000$ & $T(n)$ & $\mathrm{CT}(\mathrm{n})$ & $\$ ’ 000$ & $(1)$ & (2) & 1 \\
\hline 1987 & 6000 & 127 & 21 & 400 & 58 & 145 & 6400 & 185 & 29 & 58 & 127 & $2 \cdot 2$ \\
\hline 1988 & 5921 & 125 & 21 & 767 & 67 & 87 & 6688 & 192 & 29 & 58 & 134 & $2 \cdot 3$ \\
\hline 1989 & 5840 & 123 & 21 & 1131 & 74 & 65 & 6971 & 197 & 28 & 58 & 139 & $2 \cdot 4$ \\
\hline 1990 & 5755 & 121 & 21 & 1493 & 82 & 55 & 7247 & 203 & 28 & 58 & 145 & $2 \cdot 5$ \\
\hline 1991 & 5669 & 119 & 21 & 1851 & 90 & 49 & 7520 & 209 & 28 & 58 & 151 & $2 \cdot 6$ \\
\hline 1992 & 5580 & 117 & 21 & 2206 & 98 & 44 & 7786 & 215 & 28 & 58 & 157 & $2 \cdot 7$ \\
\hline 1993 & 5498 & 116 & 21 & 2558 & 106 & 41 & 8056 & 222 & 28 & 58 & 164 & $2 \cdot 8$ \\
\hline 1994 & 5417 & 114 & 21 & 2907 & 113 & 39 & 8324 & 227 & 27 & 58 & 169 & $2 \cdot 9$ \\
\hline 1995 & 5333 & 112 & 21 & 3253 & 121 & 37 & 8585 & 233 & 27 & 58 & 175 & 3.0 \\
\hline 1996 & 5247 & 110 & 21 & 3595 & 128 & 36 & 8841 & 238 & 27 & 58 & 180 & $3 \cdot 1$ \\
\hline 1997 & 5157 & 108 & 21 & 3933 & 135 & 34 & 9090 & 243 & 27 & 58 & 185 & $3 \cdot 2$ \\
\hline 1998 & 5064 & 106 & 21 & 4268 & 143 & 34 & 9332 & 249 & 27 & 58 & 191 & $3 \cdot 3$ \\
\hline 1999 & 4967 & 104 & 21 & 4599 & 150 & 33 & 9567 & 254 & 27 & 58 & 196 & $3 \cdot 4$ \\
\hline 2000 & 4867 & 102 & 21 & 4927 & 157 & 32 & 9794 & 259 & 26 & 58 & 201 & 3.5 \\
\hline 2001 & 4767 & 100 & 21 & 5252 & 164 & 31 & 10019 & 264 & 26 & 58 & 206 & 3.6 \\
\hline 2002 & 4665 & 98 & 21 & 5572 & 171 & 31 & 10236 & 269 & 26 & 58 & 211 & 3.6 \\
\hline 2003 & 4562 & 96 & 21 & 5888 & 178 & 30 & 10450 & 274 & 26 & 58 & 216 & $3 \cdot 7$ \\
\hline 2004 & 4457 & 93 & 21 & 6199 & 184 & 30 & 10656 & 277 & 26 & 58 & 219 & 3.8 \\
\hline 2005 & 4349 & 91 & 21 & 6506 & 191 & 29 & 10855 & 282 & 26 & 58 & 224 & 3.9 \\
\hline 2006 & 4243 & 89 & 21 & 6808 & 198 & 29 & 11051 & 287 & 26 & 58 & 229 & 3.9 \\
\hline
\end{tabular}


Table IV 200 new injuries per annum

\begin{tabular}{|c|c|c|c|c|c|c|c|c|c|c|c|c|}
\hline \multirow{3}{*}{$\begin{array}{c}\text { Year } \\
\text { of } \\
\text { expense } \\
n\end{array}$} & \multicolumn{3}{|c|}{ Projection SCI 1987} & \multicolumn{3}{|c|}{ Projection future SCI } & \multicolumn{3}{|c|}{ Projection total SCI } & \multicolumn{3}{|c|}{ Nature of costs } \\
\hline & $\begin{array}{c}\text { No. } \\
\text { surviving }\end{array}$ & $\begin{array}{l}\text { Total } \\
\text { cost } \\
\$ \mathrm{~m}\end{array}$ & $\begin{array}{c}\text { Average } \\
\text { cost }\end{array}$ & $\begin{array}{l}\text { No. } \\
\text { this } \\
\text { year }\end{array}$ & $\begin{array}{l}\text { Total } \\
\text { cost } \\
\$ \mathrm{~m}\end{array}$ & $\begin{array}{c}\text { Average } \\
\text { cost }\end{array}$ & $\begin{array}{l}\text { Total } \\
\text { no. } \\
\text { alive }\end{array}$ & $\begin{array}{c}\text { Total } \\
\text { cost } \\
\$ \mathrm{~m}\end{array}$ & Average & Initial & Recurrent & 2 \\
\hline & $P(n)$ & $\mathrm{CP}(\mathrm{n})$ & $\$ ’ 000$ & $\mathrm{~N}(\mathrm{n})$ & $\mathrm{CN}(\mathrm{n})$ & $\$ ’ 000$ & $\mathrm{~T}(\mathrm{n})$ & $\mathrm{CT}(\mathrm{n})$ & $\begin{array}{c}\text { cost } \\
\$ ’ 000\end{array}$ & (1) & $\begin{array}{l}\text { Recurrent } \\
(2)\end{array}$ & $\overline{1}$ \\
\hline 1987 & 6000 & 127 & 21 & 200 & 29 & 145 & 6200 & 156 & 25 & 29 & 127 & $4 \cdot 4$ \\
\hline 1988 & 5921 & 125 & 21 & 384 & 34 & 89 & 6305 & 159 & 25 & 29 & 130 & $4 \cdot 5$ \\
\hline 1989 & 5840 & 123 & 21 & 566 & 37 & 65 & 6405 & 160 & 25 & 29 & 131 & $4 \cdot 5$ \\
\hline 1990 & 5755 & 121 & 21 & 746 & 41 & 55 & 6501 & 162 & 25 & 29 & 133 & $4 \cdot 6$ \\
\hline 1991 & 5669 & 119 & 21 & 925 & 45 & 49 & 6594 & 164 & 25 & 29 & 135 & $4 \cdot 7$ \\
\hline 1992 & 5580 & 117 & 21 & 1103 & 49 & 44 & 6683 & 166 & 25 & 29 & 137 & $4 \cdot 7$ \\
\hline 1993 & 5498 & 116 & 21 & 1279 & 53 & 41 & 6777 & 169 & 25 & 29 & 140 & $4 \cdot 8$ \\
\hline 1994 & 5417 & 114 & 21 & 1454 & 57 & 39 & 6871 & 171 & 25 & 29 & 142 & $4 \cdot 9$ \\
\hline 1995 & 5333 & 112 & 21 & 1626 & 61 & 38 & 6959 & 173 & 25 & 29 & 144 & $5 \cdot 0$ \\
\hline 1996 & 5247 & 110 & 21 & 1797 & 64 & 36 & 7044 & 174 & 25 & 29 & 145 & $5 \cdot 0$ \\
\hline 1997 & 5157 & 108 & 21 & 1966 & 68 & 35 & 7124 & 176 & 25 & 29 & 147 & $5 \cdot 1$ \\
\hline 1998 & 5064 & 106 & 21 & 2134 & 72 & 34 & 7198 & 178 & 25 & 29 & 149 & $5 \cdot 1$ \\
\hline 1999 & 4967 & 104 & 21 & 2300 & 75 & 33 & 7267 & 179 & 25 & 29 & 150 & $5 \cdot 2$ \\
\hline 2000 & 4867 & 102 & 21 & 2464 & 79 & 32 & 7331 & 181 & 25 & 29 & 152 & $5 \cdot 2$ \\
\hline 2001 & 4767 & 100 & 21 & 2626 & 82 & 31 & 7393 & 182 & 25 & 29 & 153 & $5 \cdot 3$ \\
\hline 2002 & 4665 & 98 & 21 & 2786 & 86 & 31 & 7451 & 184 & 25 & 29 & 155 & $5 \cdot 3$ \\
\hline 2003 & 4562 & 96 & 21 & 2944 & 89 & 30 & 7506 & 185 & 25 & 29 & 156 & $5 \cdot 4$ \\
\hline 2004 & 4457 & 93 & 21 & 3100 & 92 & 30 & 7557 & 185 & 25 & 29 & 156 & $5 \cdot 4$ \\
\hline 2005 & 4349 & 91 & 21 & 3253 & 96 & 30 & 7602 & 187 & 25 & 29 & 158 & $5 \cdot 4$ \\
\hline 2006 & 4243 & 89 & 21 & 3404 & 99 & 29 & 7647 & 188 & 25 & 29 & 159 & $5 \cdot 5$ \\
\hline
\end{tabular}




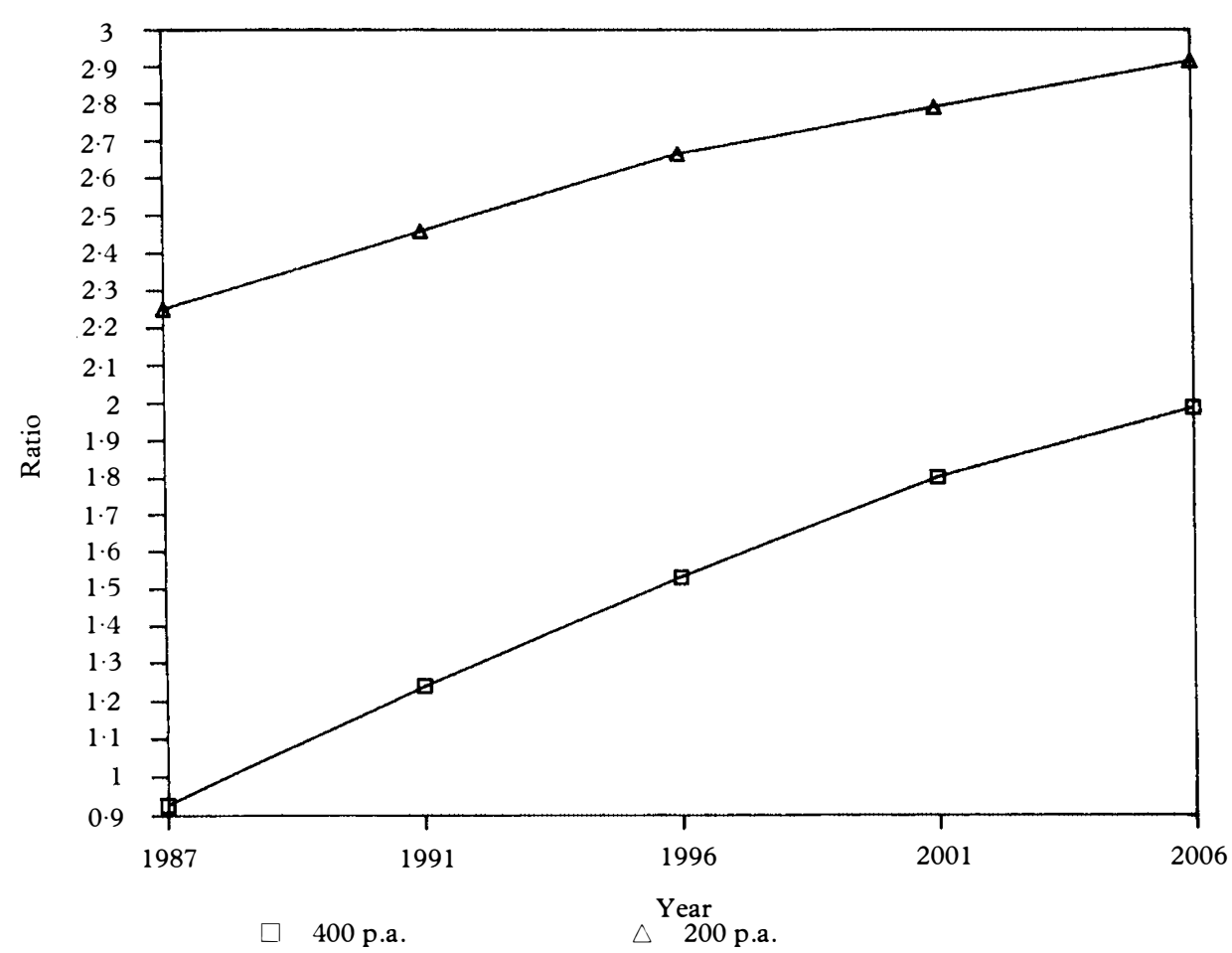

Figure 2 Ratio of recurrent to initial costs.

Table V Capital values of typical costs

\begin{tabular}{llrrrrr}
\hline Age & \multicolumn{2}{l}{ Initial cost } & \multicolumn{2}{c}{ Income replacement } & \multicolumn{2}{l}{ Ongoing costs } \\
\hline 20 & 110.0 & 180.0 & 132.9 & 132.9 & 261.0 & 495.1 \\
30 & 110.0 & 180.0 & 118.8 & 118.8 & 242.4 & 455.3 \\
40 & 110.0 & 180.0 & 98.5 & 98.5 & 213.8 & 395.5 \\
50 & 110.0 & 180.0 & 69.4 & 69.4 & 179.2 & 326.8 \\
60 & 110.0 & 180.0 & 27.4 & 27.4 & 132.9 & 252.3 \\
\hline
\end{tabular}

Costs are as set out in Methodology, projected for lifetime and discounted by an effective $2^{\circ}{ }_{0}$ per annum.

\section{Discussion}

Improving longevity and persistent incidence of spinal cord injury will cause ever increasing costs to the community, both in economic 'dollar' terms and also in terms of the pain and suffering and loss of quality of life suffered by people who have sustained this disability.

In particular the application of funds will progressively be channelled into long term care as the population of paraplegics and tetraplegics ages. This progression has obvious implications for control of the escalation in costs. In the first place costs can obviously be contained by achieving prevention of spinal cord injury. Just as important, however, is the prevention of the 'handicaps' which result from spinal cord injury: by controlling long term community costs through rehabilitation (e.g. Ikata, 1987) and application of improving tech- 
A
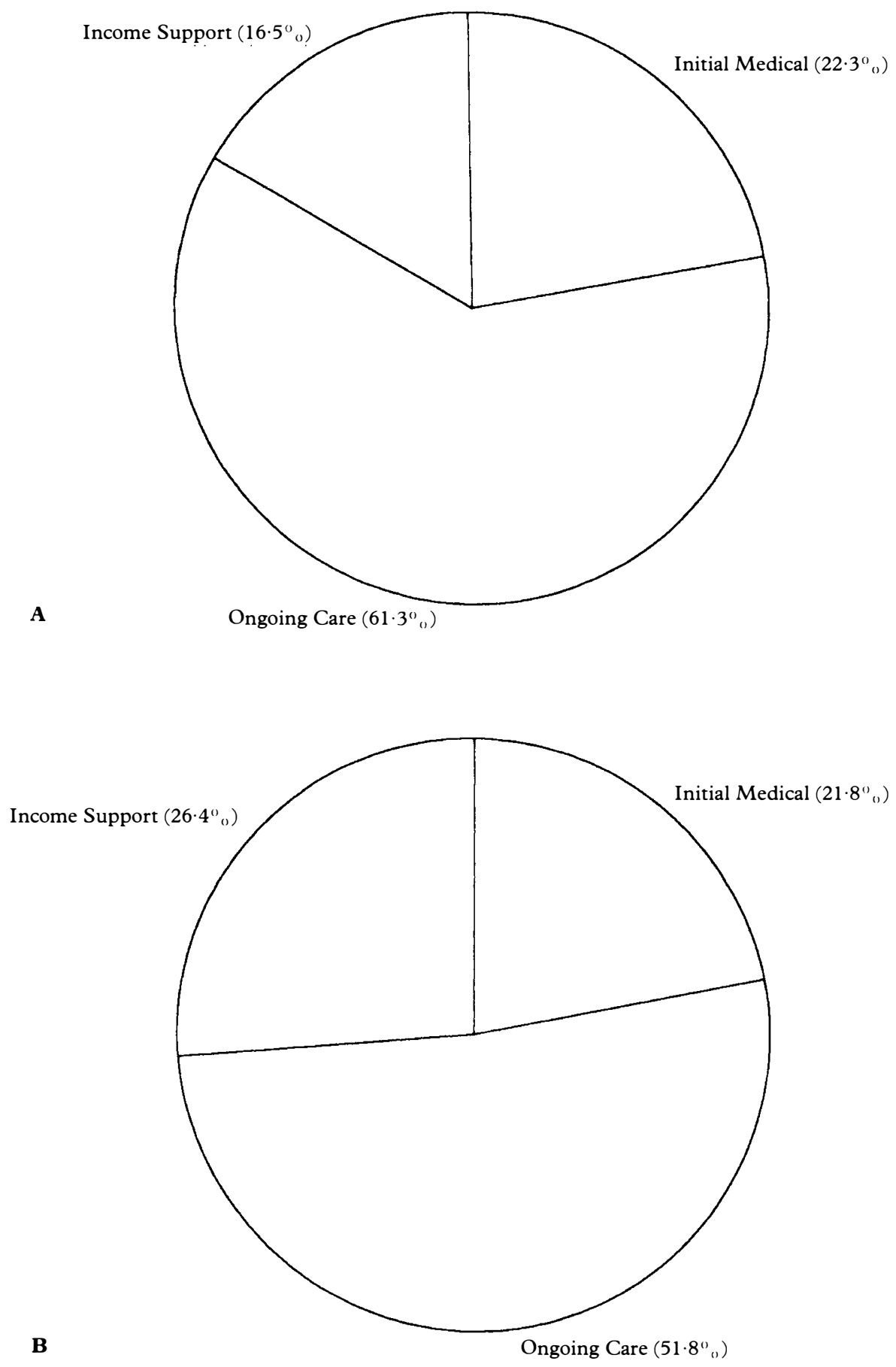

Figure 3 Analysis of costs of A 20-year-old tetraplegic patient, B 20-year-old paraplegic patient. 
nology (e.g. Van Laire and Duyjevonck, 1986) we should be able to reduce the dollar costs and at the same time reduce the non-economic costs by improving the quality of life.

Clearly there is a need for sophisticated and compatible data and information systems to evaluate the progress of any active programmes in prevention and/or rehabilitation.

\section{References}

BURKe DC, Brown DJ, BurLey HT, et al. 1986 Data collection. Knowing what we are talking about. Presented at conference '10 Years of Spinal Research', Hobart (in press).

DEVIVo MJ, Fine PR 1980 The prevalence of spinal cord injuries. A re-estimation based on life-tables. Spinal Cord Injury Digest: 1.

Donavan WH 1987 Medical-legal issues concerning spinal trauma. Paraplegia 25:305-307.

EISENBERG MG, TIERNEY DO 1985 Changing demographic profile of the spinal cord injured population: Implications for health care support systems. Paraplegia 23:335-343.

IKATA T 1987 Resettlement and employment of paraplegic patients in Japan. Paraplegia 25:308-309.

MENZIEs Foundation 1987 Technical report No. 1: Towards prevention of spinal injury. Menzies Foundation, Melbourne.

Paraplegic \& QUAdRIPLegic Association of NSW 1985 A Survey of Members 1984-5.

Van LaIre M, Duyvejonck R 1986 Environment control and social interaction. Paraplegia 24:322-325. 